\title{
CONTRIBUCIÓN DE LOS PROCESOS VERBALES AL DISCURSO NARRATIVO EN ESPAÑOL
}

\author{
(Contribuição dos processos verbais para o discurso \\ narrativo em Espanhol) \\ (The contribution of verbal processes to narrative \\ discourse in Spanish)
}

\author{
Cristina BocCIA \\ Laura HLAVACKA \\ Grisel S. SALMASO \\ (Universidad Nacional de Cuyo, Mendoza, Argentina)
}

Resumen: En este artículo exploramos, desde una perspectiva sistémico-funcional, el papel que desempeñan dos subgrupos de procesos verbales, los "procesos de decir + cualidad" y los "proceso de juicio", en la codificación de significados centrales a la creación de diferentes elementos en textos narrativos, más específicamente su contribución a la construcción de los personajes y el tenor entre ellos, al desarrollo de la acción y a la articulación de los temas de la narración. Nuestras observaciones se basan en una muestra de textos narrativos de dos autores latino-americanos, Julio Cortázar y Eduardo Galeano, y procuramos apoyar estas observaciones por referencia a las propiedades semánticas y léxico-gramaticales de los procesos bajo estudio y los patrones que estos establecen en el texto. Nos apoyamos en descripciones de transitividad desarrolladas en el marco de la Gramática Sistémico-Funcional y en trabajos de Halliday $(1971$, 2002) y Hassan $(1985,1996)$ que proponen principios para una Estilística de base Lingüística.

Palabras-clave: procesos de decir; funciones discursivas; discurso narrativo; autores latinoamericanos

Abstract: In this article we explore, from a systemic-functional perspective, the role played by two subgroups of verbal processes, "processes of saying + quality" and "processes of judgment", in encoding meanings central to the creation of different elements in narratives, more specifically their contribution to the portrayal of characters and the tenor between them, to the advancement of action and to the articulation of the more profound themes in the narratives. We base our observations on a sample of narrative texts by two hispanoamerican authors, Julio Cortázar and Eduardo Galeano, and we seek to support them by 
reference to the semantic and lexico-grammatical properties of the processes under study and to patterns they form in the text. We draw upon transitivity descriptions within Systemic Functional Linguistics and on work by Halliday (1971, 2002) and by Hassan (1985, 1996) setting forth principles for a Linguistic Stylistics.

Key-words: verbal processes; discursive functions; narrative discourse; hispano-american authors

Resumo: Neste artigo exploramos, de uma perspectiva sistêmica-funcional, o papel desempenbado pelos dois subgrupos de processos verbais, "processos de dizer + qualidade" e "processos de julgamento", ao codificar significados centrais para a criação de elementos diferentes em narrativas, mais especificamente sua contribuição para o retrato de caracteres e o teor entre eles, para o avanço da ação e para a articulação dos temas mais profundos nas narrativas. Baseamos nossas observaçoes em uma amostra de textos narrativos de dois autores hispano-americanos, Julio Cortázar e Eduardo Galeano,.e, para fornecermos evidência lingüística para a nossa análise pretendemos apoio nas propriedades lexico gramaticais e semânticas dos processos sob estudo e nos padrões que formam no texto.. Bseamo-nos em descrições de transitividade na lingüística funcional sistêmica e no trabalho de Halliday e de Hassan estabelecendo princípios para uma estilística linguística.

Palavras-chave: processos verbais. funções discursivas. discurso narrativo; autores bispano-americanos.

\section{INTRODUCCIÓN}

Los procesos verbales o del "decir" son, desde la perspectiva de la Gramática Funcional-Sistémica que se sigue en este artículo, recursos de orden experiencial, que interpretan y representan (= construe) la interacción verbal como dominio de la experiencia y las dimensiones semánticas y contextuales asociadas a ésta, entre otras, la naturaleza dialógica de la interacción verbal (preguntar, responder), la continuidad del discurso (agregar, añadir), el posicionamiento relativo de quienes interactúan y el tipo de bien que se intercambia (decir, preguntar, ofrecer, ordenar), las relaciones de poder entre quienes interactúan (encomendar, mandar, ordenar; suplicar, rogar, pedir, exigir), la modalidad (sugerir, afirmar, demostrar), la actitud del hablante (despreciar, difamar, insultar, felicitar) y la cualidad de la voz (balbucear, gritar, murmurar, susurrar).

Dada su función de interpretar y representar la interacción verbal, los procesos verbales son frecuentes en discursos en los que es preciso presentar 
este dominio de la experiencia humana. Halliday y Matthiessen (2004: 252253) señalan que este tipo de procesos es un recurso muy importante en inglés en el discurso periodístico, en el discurso académico y en la creación de la narración. En el discurso periodístico, los procesos verbales se usan en la construcción de noticias y permiten a los periodistas, según estos autores, atribuir la información a distintas fuentes, incluyendo funcionarios, expertos, testigos, etc. En el discurso académico, el uso de estos procesos, según Halliday y Matthiessen (2004), hace posible citar textualmente o reproducir lo que otros varios estudiosos han dicho, indicando, al mismo tiempo, la actitud del autor ante estas contribuciones con verbos comopoint out, suggest, claim, assert. Finalmente, en el discurso narrativo, que es el foco de este artículo, estos procesos contribuyen a la creación de la narración, ya que facilitan, como señalan Halliday y Matthiessen, la construcción de pasajes con diálogo, en base al modelo "x dijo, luego y dijo", conjuntamente con citas de lo que se dijo.

En este artículo nos centramos en dos subgrupos de procesos verbales empleados en textos narrativos y atendemos especialmente a la función que éstos cumplen a nivel discursivo en la narración. Estos procesos son (i) procesos de decir, como, por ejemplo, "balbucear", "chillar", "gritar", "susurrar", que codifican un significado adicional de "cualidad" (decir + cualidad), más específicamente de "modo del decir" asociado a la "cualidad de la voz", y (ii) procesos de decir como "alabar", "denunciar", "insultar", "maldecir", entre otros, que codifican, además del significado de "decir", un significado adicional de "juicio" (decir + juicio). Hemos elegido estos dos grupos por el interés que los mismos presentan desde el punto de vista semántico, dada la posibilidad de sub-clasificarlos con mayor grado de delicadeza a partir de sus propiedades semánticas distintivas, y porque, además, tienen una alta frecuencia en las narraciones analizadas y parecen, en virtud de su significado, cumplir, a nivel discursivo, funciones adicionales a la de construir pasajes de diálogo.

La función de estos procesos en la narración de permitir establecer pasajes de diálogo se puede comprobar en muchas de las narraciones (viñetas y cuentos) en la muestra de textos que hemos empleado y se puede apreciar, por ejemplo, en el pasaje que se reproduce a continuación, extraído de esa muestra. En este pasaje, que procede de una narración del primer volumen de Memoria del fuego, "La resurrección", del autor uruguayo Eduardo Galeano (1982), y que se basa en un mito del Perú pre-colombino y explica 
el fenómeno del carácter definitivo de la muerte, los procesos verbales que contribuyen a crear pasajes de diálogo han sido indicados en negrita:

A los cinco días, era costumbre, los muertos regresaban al Perú. Bebían un vaso de chica y decían: - Ahora, soy eterno.

... Entonces murió un hombre en Huarochirí.

Toda la comunidad se reunió, al quinto día, para recibirlo. Lo esperaron desde la mañana hasta la noche. Se enfriaron los platos humeantes y el sueño fue cerrando los párpados. El muerto no llegó.

Apareció al día siguiente. Estaban todos hechos una furia. La que más hervía de indignación era la mujer que le gritó:

- iHaragán! iSiempre el mismo haragán! iTodos los muertos son puntuales menos tú!

El resucitado balbuceó alguna disculpa, pero la mujer le arrojó una mazorca a la cabeza y lo dejó tirado en el piso ... (Galeano 1982: 39).

Los procesos verbales que nos ocupan en este artículo, más específicamente "gritar", con proyección, como cita textual (= quote), de lo dicho por la mujer como Emisor (= Sayer), y "balbucear", con una configuración que incluye "Emisor" y "Verbalización (=Verbiage)", de lo dicho por el hombre, contribuyen en este pasaje a establecer el diálogo entre una mujer y su esposo y representan, en virtud de sus propiedades semánticas y su localización en el texto, la naturaleza interactiva de la comunicación entre ambos, es decir, la toma alternativa de turnos: la mujer inicia la interacción y el hombre responde. Desde una perspectiva funcional sistémica, el diálogo pone en acto y permite negociar dimensiones interpersonales del contexto de situación, como la actitud del hablante y el tenor entre los interactuantes. Dada la propiedad de las narraciones de reproducir la realidad ("the as if character of literature", en palabras de Hassan 1996: 50) esta característica del diálogo se evidencia también en las narraciones, por lo que, si observamos el diálogo que los procesos verbales contribuyen a crear en el ejemplo anterior, advertimos que al establecer este diálogo, los procesos están poniendo en acto en la obra literaria, como en la vida, la actitud de los personajes y el tenor entre ellos. En virtud de esta propiedad de experiencializar dimensiones interpersonales del contexto, los procesos verbales considerados y el diálogo que establecen contribuyen a la construcción de aspectos importantes en la creación del texto narrativo como la caracterización de los personajes, más específicamente del estado de ánimo de éstos, ilustrado en el ejemplo anterior en la ira de la mujer que se expresa a través de una prosodia en la que el verbo "gritar" cumple un 
papel importante en la evocación de este estado afectivo; la representación del tenor entre los personajes, tal como se observa en el ejemplo presentado en el que se expresan las relaciones de poder entre ellos: la mujer "grita" y el hombre "balbucea"; y la evaluación de los eventos por parte de los personajes y la consecuente puesta en relieve del tema central de la narración: la actitud de los interactuantes que se pone de manifiesto en el ejemplo previo en el "gritar" y el "balbucear" representa una evaluación de los hechos y destaca lo inapropiado de la tardanza. Además, por su carácter de evento, estos procesos contribuyen, en complementariedad con los demás procesos, a la progresión de la narración y la creciente tensión narrativa (cada proceso verbal, como evento, contribuye a que la narración avance hacia un punto de tensión y resolución). Estas funciones parecen ser generalizables a las narraciones de carácter literario y se evidencian también, como procuraremos mostrar más adelante, en narraciones de la muestra empleada que incluyen procesos de "decir" aunque no propiamente diálogo.

El estudio que se presenta en este artículo pretende efectuar una modesta contribución al proyecto Systemics Across Languages (SAL). Verbal processes from grammar to discourse in English, Japanese, Portuguese, Spanish and Thai, establecido en 2008 en PUC en São Paolo, Brasil, y coordinado por Christian Matthiessen, Kazuhiro Teruya y Leila Barbara. El propósito de este estudio es presentar observaciones preliminares acerca de la contribución de los procesos verbales, en particular, de los subtipos de procesos indicados más arriba, al discurso narrativo, más específicamente observaciones acerca de la función de estos procesos en la construcción de los aspectos de la creación narrativa sugeridos en el párrafo anterior, así como en la articulación del tema o de los temas centrales o más profundos de las narraciones. Estas observaciones se basan en el análisis de un corpus de textos narrativos de aproximadamente 300.000 palabras, de dos autores latinoamericanos, Eduardo Galeano y Julio Cortázar. Este artículo se estructura de la siguiente manera: en primer lugar, hacemos una breve caracterización de los procesos seleccionados; luego describimos brevemente el corpus y la metodología empleada en el análisis de la función de los procesos a nivel discursivo; $y$, en la parte central del estudio, presentamos las observaciones sobre la contribución de los procesos verbales a la narración en base a dos narraciones del corpus, representativas de lo que hemos encontrado al analizar el resto del corpus. Finalmente, formulamos las conclusiones a las que hemos llegado en este estudio. 


\section{Breve CARACTERIZACIÓN DE LOS SUbGRUPOS DE PROCESOS CONSIDERADOS}

Para este trabajo hemos seleccionado dos subgrupos de procesos de entre los procesos verbales, a saber, los procesos de "decir + cualidad" y los procesos de "juicio", siguiendo la designación que se da a estos subgrupos en los documentos del proyecto SAL.

Los procesos de "decir + cualidad" se distinguen de otros procesos verbales por codificar, además del rasgo de "decir", rasgos semánticos asociados a propiedades acústicas, como, por ejemplo, el "volumen" o la "intensidad de la voz", el "tono", la "extensión o duración de los sonidos", la "claridad de la articulación", entre otros. La tabla que se presenta a continuación registra y ejemplifica los rasgos semánticos acústicos identificados en la muestra analizada y esboza una posible sub-clasificación de los procesos en función de éstos:

Tabla 1 - Sub-clasificación de los procesos de "decir + cualidad"

\begin{tabular}{|l|l|l|}
\hline Rasgo experiencializado & Ejemplo \\
\hline \multirow{2}{*}{ volumen/ intensidad } & alto/amplificado & $\begin{array}{l}\text { aullar, chillar, clamar, gritar, rugir, resoplar, } \\
\text { tronar, vociferar }\end{array}$ \\
\cline { 2 - 3 } & bajo & balbucear, musitar, murmurar, secretear, susurrar \\
\hline \multirow{2}{*}{ tono/timbre } & agudo & aullar, chillar \\
\cline { 2 - 3 } & grave & roncar, rugir \\
\hline dicción/articulación & balbucear, murmurar, tartamudear \\
\hline melodía & cantar, canturrear, tararear \\
\hline extensión/duración & aullar \\
\hline
\end{tabular}

Como sugiere la tabla, muchos de estos procesos codifican más de un rasgo. Tal es el caso de "balbucear", que codifica el rasgo de intensidad baja y de dicción o articulación poco clara, y de "aullar", que en la lengua en general se combina con participantes animales (lobo, perro) pero que en nuestra muestra se instancia en combinación con participantes humanos y con proyección de tipo locución, cita textual (= quote), y codifica el rasgo de tono agudo y extensión o duración larga. Es importante indicar que muchos de los procesos asociados a este grupo (aullar, balbucear, gritar, murmurar, musitar, roncar, rugir) no son primariamente procesos verbales, sino que, 
más bien, parecerían representar lo que Matthiessen categoriza como procesos de comportamiento paraverbales (Matthiessen 1995: 251), que, en principio, no tienen la capacidad de proyectar otra cláusula, pero que, en la narración, se ponen al servicio de lo verbal y adquieren la capacidad de proyectar otra cláusula, generalmente en forma de cita textual. Hemos incluido en este grupo algunos procesos de comportamiento de carácter fisiológico (jadear) y psicológico (gemir, sollozar), de escasa frecuencia en la muestra empleada, que tienen algunos rasgos acústicos o articulatorios que pueden categorizarse como una "cualidad" o un "modo del decir" (jadear $=$ decir en medio de espiraciones audibles y entrecortadas; gemir y sollozar $=$ decir con un llanto entrecortado o con voz lastimera).

Hemos observado en el corpus que las propiedades acústicas señaladas más arriba parecerían conferir a estos procesos el potencial de evocar afecto (dolor, enojo, temor), lo que se puede apreciar en el ejemplo de la Introducción, donde el proceso "gritar", asociado a la mujer como Emisor, evoca enojo de su parte y el proceso "balbucear", asociado al hombre como Emisor, vergüenza o temor. También hemos observado que las propiedades acústicas codificadas por estos procesos se realizan no solamente en el proceso, sino, también, en otros elementos de la figura o en figuras en cláusulas dependientes en complejos clausales. En tales casos el proceso en la figura de la cláusula independiente simple o en la cláusula principal de un complejo puede ser un proceso verbal de carácter más genérico ("hablar” en el ejemplo que se reproduce abajo) o un proceso no primariamente verbal, sino, generalmente, material (“atacar" en el ejemplo que se reproduce más abajo). En este último caso, la figura adquiere un significado verbal por las propiedades acústicas que se codifican en algún otro de sus constituyentes o en un proceso de una cláusula dependiente. A continuación ejemplificamos algunas de estas realizaciones:

Codificación en un participante:

... no cesan los aullidos de agonía de las jovencitas de Salem ... (Galeano 1982: 306-7)

Codificación en una circunstancia de modo:

... lo ataca a viva voz (Galeano 2006: 225)

... hablaba a gritos y siempre por la nariz: (intensidad y dicción; Cortázar 1996: 304)

La identificación de figuras en el corpus en las que la lexicalización de los rasgos acústicos identificados se da en elementos del entorno del 
proceso aporta evidencia en favor de la existencia de estos rasgos que están infundidos cuando se codifican en el proceso.

El otro subgrupo de procesos, los de “juicio”, están caracterizados en la bibliografía consultada como procesos de impacto verbal (Matthiessen 1995: 285), que no tienen la capacidad de proyectar otra cláusula y que incluyen en la configuración asociada, además del Emisor, un participante que representa el "blanco" o el "objetivo" del impacto verbal (= Target). Estos procesos son de carácter efectivo (Davidse 1999: 310), y tienen una cierta proximidad semántica con los procesos materiales efectivos con un participante "Meta" en su figura (Matthiessen 1995: 285; Halliday y Matthiessen 2004: 256), ya que el participante “Target" se ve, de alguna manera, afectado por la acción verbal del Emisor. La proximidad semántica de estos procesos a los procesos materiales efectivos se manifiesta en español por el hecho de que ambos pueden incluir en la configuración asociada al proceso un participante indirectamente afectado por la acción, en negrita en los siguientes ejemplos:

Juan me rompió la guitarra (= Juan rompió la guitarra y eso me afecta indirectamente; proceso material)

Nadie me insulta a mi hijo (= Si alguien lo hace, eso me afecta indirectamente; proceso verbal de juicio).

Los procesos de este subgrupo, como su nombre lo indica, codifican un juicio sobre el participante objeto de impacto verbal (= Target) y podrían, por lo tanto, sub-clasificarse a la luz de las categorías del subsistema de Juicio, dentro del Sistema de Valoración propuesto por Peter R. R. White y James R. Martin en The Language of Evaluation. Appraisal in English (White y Martin 2005: 52-56). Los procesos de este tipo registrados en el corpus empleado para este estudio no son suficientes para intentar una subclasificación, pero, en base a una muestra muy reducida de estos procesos conformada a partir de instancias en Internet, hemos podido esbozar una sub-clasificación de los mismos, según la orientación que muestran las instancias a expresar un juicio del tipo estima social (capacidad, tenacidad, normalidad), del tipo sanción social (propiedad, veracidad) o de ambos tipos. Como se aprecia en la tabla el juicio puede ser positivo o negativo y se puede expresar privada o públicamente. Además, en el caso de los procesos de sanción social, parecería haber un rasgo semántico que codifica la sanción, 
en algunos casos, como "infundada”, o bien, que expresa un juicio negativo sobre el mismo Emisor, quien enjuicia "sin fundamento":

Tabla 2 - Sub-clasificación de los procesos de "juicio”

\begin{tabular}{|c|c|c|}
\hline Estima social & Sanción social & Juicio \\
\hline $\begin{array}{l}\text { alabar (positivo, privado o } \\
\text { público); burlarse de (negativo, } \\
\text { privado o público); despreciar } \\
\text { (negativo, privado o público), } \\
\text { elogiar (positivo, privado o } \\
\text { público); menospreciar (negativo, } \\
\text { privado o público); ovacionar } \\
\text { (positivo, público); ridiculizar } \\
\text { (negativo, público); vitorear } \\
\text { (positivo, público). }\end{array}$ & $\begin{array}{l}\text { acusar (negativo, público); } \\
\text { calumniar (negativo, público, } \\
\text { infundado); censurar (negativo, } \\
\text { público); condenar (negativo, } \\
\text { público); desprestigiar (negativo, } \\
\text { público); difamar (negativo, } \\
\text { público, infundado); insultar } \\
\text { (negativo, privado o público); } \\
\text { reprender (negativo, privado o } \\
\text { público); reprobar (negativo, } \\
\text { privado o público). }\end{array}$ & $\begin{array}{l}\text { abuchear (negativo, } \\
\text { público); aclamar } \\
\text { (positivo, público); } \\
\text { aplaudir (positivo, } \\
\text { público); criticar } \\
\text { (negativo, privado } \\
\text { o público); ensalzar } \\
\text { (positivo, privado o } \\
\text { público). }\end{array}$ \\
\hline
\end{tabular}

Al igual que en el caso de los procesos de "decir + cualidad", las propiedades semánticas distintivas de los procesos de "juicio" pueden codificarse no solo en el proceso, sino en elementos del entorno del proceso, que, en tales casos, es de orden más genérico:

Codificación del juicio en un participante:

... lee ... sonoras alabanzas a Dios (Participante Verbalización, Galeano 2006: 269)

Las murgas de carnaval de tradición respondona, siempre burlonas del poder, no pueden cantar las palabras... (Participante Atributo, Galeano 2006: 279)

Los poetas locos van al muere y los poetas normales besan la espada y cometen elogios y silencios (Participante Alcance $=$ Range; Galeano 2006: 299)

\section{Codificación del juicio en una Circunstancia:}

... claman contra el presidente; canta contra el poder; firman un manifiesto contra la censura (Circunstancia de causa, Galeano 2006: 243, 264, 288)

Codificación del juicio en el pos-modificador de un elemento nominal:

Al cumplirse un año del golpe de Estado, está enviando algo así como un memorial de agravios, constancia de las infamias ... (Galeano 2006: 288).

Codificación del juicio en una cláusula dependiente de proyección (locución):

Cary dijo: "Eres un cobarde, un canalla, y además un mal poeta”, ... (Cortázar 1996: 36) 
En el análisis que presentamos en este artículo, tendremos en cuenta tanto los procesos con rasgos infundidos de "cualidad de la voz" y de "juicio", como los procesos en los que dichos rasgos se realizan en elementos del entorno del proceso. A juzgar por las observaciones que hemos podido hacer en la muestra de textos, todos los procesos verbales cumplen, en la narración, las funciones anticipadas en la Introducción de este artículo. Al presentar nuestras observaciones sobre las funciones de los subgrupos de procesos seleccionados, procuraremos indicar cuál es el aporte peculiar de estos subgrupos, en virtud de los rasgos semánticos identificados para cada subgrupo, a la creación de la narración.

\section{Diseño Del ESTUdio}

El presente estudio se basa en una muestra de textos narrativos de dos autores latinoamericanos, Eduardo Galeano y Julio Cortázar, extraída de un corpus algo más amplio, que empezamos a conformar en 2009. Las narraciones del primero de estos autores proceden de los tres volúmenes del libro Memoria del fuego (Galeano 1982, 2006), una colección de mitos, leyendas, viñetas y otras narraciones de extensión y características comparables, que reconstruye la historia y la cultura latinoamericana de la época pre- y poscolonial a partir de fuentes varias, resignificadas por el autor desde su posicionamiento particular frente a los hechos narrados. En el caso de Julio Cortázar, las narraciones se pueden caracterizar como cuentos de profundización psicológica en los personajes, que muestran una preocupación del autor por las relaciones interpersonales. La selección de las narraciones ha estado motivada por la importancia de ambos autores y por la vigencia de su obra, e incluye distintos subgéneros y temas narrativos.

El presente estudio es de carácter exploratorio y cualitativo, y se basa en el registro de las instancias de los procesos bajo análisis y de las figuras asociadas a éstos, y en la observación de su función en los textos analizados. Estos procedimientos de registro y observación han permitido determinar rasgos léxico-gramaticales y, en algunos casos, patrones significativos de tales procesos, que aportan evidencia sobre las funciones que los mismos cumplen en el texto. Halliday señala (1971, 2002: 100-102) la significación estilística de los datos numéricos y la importancia de que toda estilística sea cuantitativa y contrastiva, aunque agrega que el análisis estilístico no se reduce a un simple conteo de propiedades. El presente no es un estudio 
estrictamente cuantitativo ni contrastivo, en el que se ofrezcan datos numéricos acerca de las instancias de ocurrencia de los procesos estudiados o se comparen estos datos con la frecuencia de ocurrencia de otros procesos (materiales, mentales, relacionales, etc.) en el texto analizado o en otros textos, o con las probabilidades de ocurrencia de los procesos de "decir" o subtipos de estos en particular para la lengua en general. Un estudio de este tipo no es posible en esta etapa de la investigación. En el análisis y la argumentación que llevamos adelante en el cuerpo del artículo procuramos, sin embargo, atendera los estándares de una Estilística Lingüística como la definieron Halliday y Hassan (Halliday 1971, 2002; Hassan 1985; Hassan 1996) y al principio funcional sistémico de apoyar toda generalización sobre la lengua o sobre artefactos verbales en evidencia lingüística. Así, tratamos de establecer rasgos que se relacionan con ciertos aspectos de la creación del texto narrativo y, en la medida de lo posible, establecemos los patrones léxico-gramaticales que aporten evidencia en favor de nuestras generalizaciones. En el análisis, partimos de lo que Hassan llama una impresión contundente (= overbearing impression) y procuramos constatar esta impresión a partir de propiedades léxico-gramaticales de los textos y, cuando es posible, de regularidades. Para el análisis del tema o de los temas de las narraciones, hemos considerado también sus observaciones sobre la propiedad de doble articulación o articulación simbólica de los artefactos literarios (Hassan 1996: 50).

\section{ANÁLISIS Y DisCUSIÓN}

En esta sección presentamos las observaciones que hemos recogido del análisis de dos narraciones, el cuento de Julio Cortázar "Las manos que crecen" (Cortázar 1996: 36-42) y la viñeta de Eduardo Galeano "La casa de Neruda", del tercer volumen de la trilogía Memoria del fuego (Galeano 2006: 262-263). Analizamos dos narraciones solamente por limitaciones de espacio, pero el análisis de otras narraciones en el corpus sugiere que las observaciones sobre las funciones de los procesos verbales que aquí presentamos serían generalizables. El hecho de que las narraciones seleccionadas presenten temáticas distintas y preocupaciones distintas en los autores, refuerza las similitudes encontradas en cuanto a la función de los procesos verbales estudiados a nivel discursivo. 


\subsection{Observaciones sobre los procesos verbales de "decir + cualidad" y de "juicio" en "Las manos que crecen" de} Cortázar

En el cuento "Las manos que crecen" (Cortázar 1996: 36-42), los procesos verbales pertenecientes a las categorías "decir + cualidad" y "juicio" contribuyen a la construcción de este texto narrativo mediante la expresión del punto de vista del narrador, el establecimiento, en complementariedad con otros tipos de procesos, del conflicto que desencadena la 'complicación' en la narración, y la caracterización de los personajes y el establecimiento del tenor entre ellos. Asimismo, estos procesos contribuyen a articular significados más generales, que expresan los temas o las tesis centrales del texto narrativo así como también la perspectiva o el punto de vista del autor.

Los personajes principales de "Las manos que crecen" son Cary y Plack, dos compañeros de trabajo que parecen tener un conflicto entre ellos no claramente especificado en el cuento. La acción comienza cuando Cary insulta a Plack y éste lo golpea sin piedad. Luego de golpear a Cary, las manos de Plack crecen desmesuradamente, a un punto tal que finalmente se las deben cortar. Consideramos, en esta sección, cinco pasajes de este cuento en los que se instancian procesos verbales de los tipos seleccionados para este estudio y, en cada uno de ellos, consideramos la función que los mismos cumplen.

El primer pasaje, (1), que se reproduce a continuación, proviene del comienzo del cuento, donde se establece la complicación que desencadena la acción, y contiene un proceso que pertenece a la categoría "juicio", destacado en negrita en el ejemplo junto con la locución que proyecta:

(1) Él no había provocado. Cuando Cary dijo: "Eres un cobarde, un canalla, y además un mal poeta", las palabras decidieron el curso de las acciones, tal como suele ocurrir en esta vida.

Plack avanzó dos pasos hacia Cary y empezó a pegarle. (Cortázar 1996: 36)

El juicio de Cary, relativo a la tenacidad (= cobarde), propiedad (= canalla) y capacidad (= un mal poeta) de Plack, no está codificado 
en el proceso de la cláusula principal, que es de carácter más genérico ("decir"), sino en la locución que lo acompaña como cláusula dependiente de proyección. Este pasaje contribuye, así, a la construcción del punto de vista del narrador, quien toma distancia de los hechos, en virtud de la selección de un verbo que no codifica ningún rasgo adicional que exprese su punto de vista, y deja que el lector acceda directamente a las palabras de los personajes. El punto de vista sería distinto si el proceso seleccionado hubiese sido "censurar" ("lo censuró"), por el cual el narrador sería fuente de evaluación acerca del tipo de decir como expresión de un juicio negativo.

Además de contribuir a construir el punto de vista del narrador, el proceso de "juicio" en (1) contribuye a establecer el tenor entre los personajes. Este proceso, en complementariedad con los procesos materiales que codifican las acciones de Plack, muestra que la relación entre Plack y Cary radica en la necesidad de establecer poder: Cary expresa un juicio negativo acerca de Plack, lo insulta, podríamos decir, y Plack golpea. Ambos afirman su poder mediante acciones que tienen un impacto negativo en el otro: Cary mediante una acción de orden verbal que impacta negativamente sobre Plack por la valoración negativa que comunica; Plack mediante una acción de orden material que impacta sobre Cary afectándolo físicamente, pero que también tiene una dimensión semiótica de comunicar poder. Como dijimos en la Introducción, desde una perspectiva funcional sistémica, el diálogo pone en acto ( = enacts) y permite negociar las relaciones de poder y solidaridad entre los interactuantes. Si bien en este pasaje no hay estrictamente diálogo, se podría decir que hay una interacción entre los personajes que se asemeja a una relación dialógica, con toma de turnos (uno inicia y el otro responde, aunque la respuesta no es verbal), y que pone en acto su pugna por el poder.

El tenor entre los participantes que el proceso verbal contribuye a construir es funcional a la acción en el cuento, por lo que el proceso verbal, en complementariedad con otros procesos, también ayuda a la puesta en marcha y la progresión de la acción. En efecto, el proceso verbal "decir" en el pasaje que analizamos y el juicio que éste proyecta se complementan con procesos materiales y mentales para construir el evento que constituye la "complicación" que desencadena la acción en el cuento: Cary expresa un juicio negativo de Plack, esta acción verbal mueve a Plack a golpear a Cary y, luego de esta pelea, las manos de Plack comienzan a crecer. Por lo tanto, la actividad verbal de juicio inicia la cadena de eventos que ponen 
en movimiento la acción del cuento, si bien la función que éste cumple de contribuir al desarrollo de la acción se logra en complementariedad con otros procesos. El sustantivo anafórico "palabras" en la cláusula siguiente permite compactar el juicio y presentarlo como participante del proceso mental "decidir". De esta manera se personifica a las palabras que condensan el juicio (= se les confiere conciencia), se las representa como el "experimentante" del proceso mental "decidir" y, mediante la secuenciación de los procesos en el pasaje, se establece una relación lógica de causa-consecuencia entre el proceso verbal y las acciones que siguen ("las palabras decidieron el curso de las acciones"), que se codifican a través de los procesos materiales "avanzar" y "pegar".

Es significativo que sea un proceso de juicio de carácter negativo el que contribuya, entre otros procesos, a la caracterización del tenor entre los personajes y al establecimiento de la complicación que pone en funcionamiento la cadena de eventos que constituyen la acción en el cuento. La expresión de una valoración negativa del interlocutor por parte del hablante pone en acto las relaciones de poder entre los interactuantes y puede desencadenar, en la interacción diaria y en las interacciones que semejan las interacciones diarias en las narraciones literarias ("as if interactions"), una reacción que lleve a la acción verbal o física. En esto radica el potencial que tienen los procesos de juicio de representar el tenor entre los participantes y poner en marcha la acción en el cuento.

En el segundo pasaje que hemos seleccionado para este análisis (2), que procede del episodio final del cuento y que se reproduce a continuación, los procesos verbales de "decir + cualidad" y de "juicio" cumplen funciones comparables a las registradas para estos procesos en el pasaje anterior:

(2)

Cómo estás, Plack? - preguntaba Cary, con voz estrangulada.

¡Oh, gran imbécil! apostrofó Plack, mirando a Cary con ojos brillantes (Cortázar 1996: 41)

Los dos procesos verbales en este pasaje y las figuras asociadas a ellos contribuyen a la representación de cambios en los personajes, a partir de lo que dicen y cómo lo dicen, y también a la representación del cambio en el tenor entre ellos. Como se advierte en el texto, después de la tragedia que ha sufrido Plack, Cary está triste, angustiado, tanto que apenas puede articular 
su pregunta. Esto se muestra en la circunstancia "con voz estrangulada", que forma parte de la figura del verbo "preguntar" y que ubica esta figura en el espacio semántico de los verbos de "decir + cualidad" (dicción poco clara), los cuales evocan, como dijimos en la sección 2., afecto (en este caso infelicidad: angustia). Plack, por el contrario, tiene la misma actitud desafiante del comienzo, sólo que esta vez la expresa verbalmente. Su ímpetu se muestra, al hablar, a través del proceso "apostrofar" (= dirigir la palabra con vehemencia) y del juicio expresado en la locución: "iOh, gran imbécil!”. Es importante señalar cómo en las narraciones los procesos que proyectan juicio, como "lo apostrofó", en este caso, contribuyen no tanto a la caracterización de quien es blanco de juicio (Target) sino, más bien, de quien es la fuente del juicio, del Emisor. En este cuento de Cortázar, por ejemplo, lo que el juicio de Plack revela sobre Cary no es de particular interés. Lo que sí es de interés es lo que el juicio revela acerca del propio Plack: su insistencia obsesiva en la pugna por el poder, a pesar de las consecuencias de esta actitud que ha podido vislumbrar y del cambio en la actitud de Cary. En virtud de la actitud que los procesos expresan, estos contribuyen también a reformular el tenor entre los personajes en virtud del efecto distinto que los eventos de la historia han tenido en ellos. El proceso en el que Cary es Emisor refleja un posicionamiento distinto de sí mismo y de su interactuante en la relación. El proceso en el que Plack es Emisor no refleja un cambio de este tipo, pero el primero de ellos deja entrever lo inexorable del cambio en la relación, que Plack mismo no advierte hasta el final en el cuento.

Al funcionar como eventos en la narración, los procesos verbales en este pasaje también contribuyen a avanzar la acción hacia el punto máximo de tensión. La pregunta de Cary enfurece a Plack y causa una reacción primero verbal, la expresión de un juicio insultante que contribuye a que la tensión de la acción crezca, y luego a una material que constituye el punto de máxima tensión en el cuento, en el que Plack descubre que no ha soñado y que efectivamente ha perdido las manos. Más importante, quizás, sea destacar cómo el empleo de procesos de "decir + cualidad" (preguntar con voz estrangulada) y de juicio (iOh maldito imbécil”, lo apostrofó), asociados respectivamente a uno u otro personaje, contribuyen a poner de relieve la distinta evaluación de los hechos por parte de Cary y Plack como consecuencia de su distinta conciencia de éstos y a lograr el efecto final del cuento. 
En los pasajes (3), (4) y (5), que se reproducen a continuación, provenientes de la parte central del cuento, que se desarrolla entre el evento inicial y el final, se registran procesos que codifican rasgos, en el proceso mismo o en el entorno de éste, de "cualidad de la voz: intensidad", más específicamente, "maldecir en voz baja” y "murmurar" (2 instancias):

(3)

(Contexto: "Plack alcanzaba ahora la salida. Apenas podía moverse, arrastrando las manos por el suelo. A cada irregularidad del embaldosado sentía el erizamiento furioso de sus nervios.")

Empezó a maldecir en voz baja. (Cortázar 1996: 37)

(4)

(Contexto de ejemplo: Las manos de Plack tienen en este momento un tamaño inconmensurable. El co-texto inmediato del ejemplo es el siguiente: "Pensó: dejarlas aquí. Lo pensó como si fuese posible, seriamente, ...")

- Absurdo - murmuró, pero la palabra era como una caja vacía (Cortázar 1996: 38)

(5)

Tomaré un taxi - murmuró, empezando lentamente a desesperarse ... (Cortázar, 1996: 38)

La circunstancia "en voz baja” en el pasaje (3), contribuye a representar el estado de ánimo de Plack en un momento en que la acción crece en tensión, expresando una actitud de mesura que parecería, en una primera impresión, contradecirse con la desesperación que se apodera de él al comprobar que sus manos crecen descontroladamente. La cualidad de "intensidad baja de la voz" denota que su desesperación frente a la situación que está viviendo es contenida o mesurada, pese a que está pasando por una circunstancia espantosa e inusual y "[siente] el erizamiento furioso de sus nervios". Los procesos en (4) y (5) denotan la misma actitud refrenada de Plack que en (3). En (4) Plack habla nuevamente en voz baja (= murmura), lo que muestra la forma en la que contiene sus emociones aun estando en un estado de consternación tal como para pensar en abandonar sus manos. En (5) se muestra nuevamente la forma en la que Plack refrena sus emociones. Hay un claro contraste entre la desesperación de Plack y la expresión de la misma mediante un murmuro. Es importante recordar en este punto que Plack está en un lugar público, lo que explica el intento de refrenar sus 
emociones, comunicado en el discurso a través de procesos de decir con la cualidad de "baja intensidad de la voz" que parecen conformar un patrón en esta sección de la narración.

Ahora bien, estas funciones que hemos identificado en los pasajes anteriores de establecer la complicación en el cuento y la caracterización de los personajes y del tenor entre ellos sirven a la articulación del tema del texto y del punto de vista o la perspectiva del autor frente a los hechos o situaciones representados en el cuento. Una característica muy particular de los cuentos de Cortázar es que el autor plasma en ellos su pericia para mostrar de manera vívida y realista las características de personalidad de los personajes y las relaciones interpersonales entre ellos. En "La manos que crecen", los procesos verbales, como se dijo anteriormente, contribuyen a la caracterización de los personajes y a la creación del tenor entre ellos, constituyendo un recurso utilizado por el autor para mostrar cómo se comportan y relacionan estos dos personajes irascibles, Plack y Cary, en la pugna por el poder. Los procesos verbales ilustrados en los cinco ejemplos anteriores, en sí mismos y en conjunción con procesos materiales, parecieran contribuir a la vez a articular significados en el texto relacionados con las ideas o valores del autor. Hay muchas lecturas posibles de los cuentos de Cortázar y de este cuento en particular. Una de ellas podría ser que las palabras violentas generan violencia física y que la violencia trae aparejadas consecuencias nocivas para quienes sucumben a ella: algo de su condición de persona en ellos se deforma y atrofia, algo se cercena y se vuelven objeto de compasión. Hay así una doble articulación o articulación simbólica en el texto, en el sentido de Hassan, donde los patrones que los procesos verbales establecen por sí mismos o en complementariedad con otros procesos son la "verbalización" de las tesis centrales del cuento. (Hassan 1996: 54-56)

\subsection{Observaciones sobre los procesos verbales de "juicio" y de "decir + cualidad" en "La casa de Neruda" de Galeano}

En este apartado, se analizará un segmento de uno de los textos incluidos en la colección El siglo del viento de Eduardo Galeano, perteneciente a su trilogía Memoria de Fuego. Se trata de la viñeta titulada "1973, Santiago de Chile, La casa de Neruda”, que se reproduce a continuación: 
(6)

"En medio de la devastación, en su casa también despedazada a golpes de hacha, yace Neruda, muerto de cáncer, muerto de pena. Su muerte no alcanzaba, por ser Neruda hombre de mucho sobrevivir, y los militares le han asesinado las cosas: han hecho astilla su cama feliz y su mesa feliz, han destripado su colchón y han quemado sus libros, han reventado sus lámparas y sus botellas de colores, sus vasijas, sus cuadros, sus caracoles. Al reloj de pared le han arrancado el péndulo y las agujas; y al retrato de su mujer le han clavado la bayoneta en un ojo.

De su casa arrasada, inundada de agua y barro, el poeta parte hacia el cementerio. Lo escolta un cortejo de amigos íntimos, que encabeza Matilde Urrutia. (Él le había dicho: Fue tan bello vivir cuando vivías.)

Cuadra tras cuadra, el cortejo crece. Desde todas las esquinas se suma gente, que se echa a caminar a pesar de los camiones militares erizados de ametralladoras y de los carabineros y soldados que van y vienen, en motocicletas y carros blindados, metiendo ruido, metiendo miedo. Detrás de alguna ventana, una mano saluda. En lo alto de algún balcón, ondula un pañuelo. Hoy hace doce días del cuartelazo, doce días de callar y morir, y por primera vez se escucha la International en Chile, la Internacional musitada, gemida, sollozada más que cantada hasta que el cortejo se hace procesión y la procesión se hace manifestación y el pueblo, que camina contra el miedo, rompe a cantar por las calles de Santiago a pleno pulmón, con voz entera, para acompañar como es debido a Neruda, el poeta, su poeta, en el viaje final." (Galeano 2006: 262-263)

A partir del análisis de este texto narrativo, intentaremos ilustrar la contribución de los procesos del decir que nos ocupan en este artículo. Nos interesa mostrar, como procuramos hacerlo a partir del cuento de Cortázar - un texto narrativo distinto, por los hechos que narra, sus personajes, su temática y las preocupaciones de su autor -, cómo estos procesos del decir en particular contribuyen a construir los significados que son clave en términos de los elementos que componen un texto narrativo, tales como el incremento de la tensión y su posterior distensión, la caracterización de los personajes y las relaciones de tenor que se establecen entre ellos y, finalmente, la construcción de los temas centrales del texto así como de la ideología de Galeano.

La funcionalidad de estos mismos procesos de decir se relaciona, como en el cuento anterior, con la construcción de la caracterización de los personajes por medio de la evocación de sus emociones (el temor, la angustia, la tristeza, la necesidad de expresar su dolor) así como de sus atributos (su coraje, entereza, solidaridad). Estas emociones y atributos no son explicitados en el texto sino que son evocados por los rasgos semánticos 
que enriquecen la actividad verbal: el modo en el que se dicen las cosas, el volumen, las características de la articulación y las manifestaciones físicas de las emociones, como en "la Internacional musitada, gemida, sollozada más que cantada" y "el pueblo rompe a cantar, a pleno pulmón, con voz entera". El conjunto de rasgos semánticos asociados a la actividad verbal evoca vívidamente las emociones y los atributos de los personajes constituyéndose así en elementos funcionales a la caracterización en la narración, como procuraremos demostrar a continuación.

La viñeta se inicia con la descripción de la devastación y el saqueo de la casa de Neruda, quien ha muerto de cáncer a pocos días del golpe militar de 1973 en Chile. Los militares han arrasado la casa y han destrozado las pertenencias de su dueño. Se incluyen detalles de la violencia y crueldad con la que han destruido el lugar ("han hecho astillas su cama feliz y su mesa feliz"; "al retrato de su mujer le han clavado la bayoneta en un ojo"). La imagen evoca la crueldad con que estas acciones se han llevado a cabo, como si al mismo Neruda hubiesen asesinado, "por ser Neruda hombre de mucho sobrevivir".

El primer evento de la secuencia de acontecimientos en este texto narrativo es la partida de Neruda seguida por un cortejo, inicialmente de sus amigos íntimos, hacia el cementerio. El cortejo aumenta, cuadra tras cuadra. Este incremento en el número de personas ("el cortejo crece", "se suma gente", "el cortejo se hace procesión y la procesión se hace manifestación y el pueblo...”), acompaña la intensificación de las emociones contenidas y su gradual manifestación verbal. Las tímidas y temerosas expresiones de dolor, inicialmente gestuales ("una mano saluda”, "ondula un pañuelo"), son seguidas por "la Internacional, musitada, gemida, sollozada". Se refleja un gradual aumento de la intensidad de las emociones expresadas así como del vigor de su manifestación: desde la mano que saluda detrás de una ventana, hasta el sollozo que manifiesta físicamente el dolor del cortejo. Si bien no es solo la actividad verbal la que construye el aumento de la tensión, que también es creada por el aumento gradual de los participantes en el cortejo que se vuelcan a las calles, la manifestación verbal por medio de la Internacional, inicialmente "musitada", luego "gemida" y luego "sollozada", contribuye significativamente a marcar la tensión creciente. El Tema marcado "por primera vez", realza la importancia de la actividad verbal. Es esta la primera vez que el pueblo entona en Chile la Internacional. La acción se suspende aquí momentáneamente para describir las cualidades 
del canto. Los rasgos relacionados con el volumen de la articulación en "musitada", que codifican el temor inicial con la que los manifestantes se expresan, la característica de articulación en "gemida" que evoca el dolor de los participantes y la manifestación física del "sollozo" con la que culmina la expresión del dolor de los manifestantes, se combinan para construir una prosodia claramente relacionada con el aumento del afecto de los personajes que participan del cortejo. La importancia de la actividad verbal es intensificada por la actividad verbal que se codifica en "musitada", "gemida" y "sollozada". Esta secuenciación contribuye a incrementar la tensión. Los rasgos semánticos infundidos se disponen naturalmente en un continuo de intensidad creciente en términos de su volumen y de la intensidad del afecto que evocan. Adicionalmente, se realza la importancia de la actividad verbal por medio de la expresión de contra-expectativa "más que cantada": la Internacional, más que cantada es musitada, gemida y sollozada, siendo esta una expresión más vehemente y apasionada que el canto mismo. Es decir, que es por medio de la actividad verbal y, en particular de las emociones codificadas en los rasgos semánticos que se incluyen en la construcción de la actividad verbal ("musitada", "gemida" y "sollozada"), que el texto avanza hacia un punto de máxima tensión y que se construye la reacción de los personajes a los eventos sucedidos en torno a la muerte de Neruda.

La tensión llega a su máxima expresión cuando 'el pueblo, que camina contra el miedo, rompe a cantar por las calles de Santiago a pleno pulmón, con voz entera'. La actividad material de los pobladores de volcarse a las calles, enfrentar a su antagonista (el miedo infundido por los militares), y su determinación por acompañar a su poeta es complementada por la expresión verbal del pueblo que con vigor inicia su canto. El complejo verbal "rompe a cantar" incorpora la semántica de fase iniciativa en "rompe a" y la de vigor expresando así la explosión de emoción que distiende la tensión creada. La actividad verbal se asocia a este vigor y al volumen del canto "a pleno pulmón, con voz entera". Parece evocarse también la propiedad moral positiva de quienes enfrentan al miedo cantando con voz "entera" y oponiendo así su comportamiento íntegro y valiente a la autoridad violenta y cruel del opresor. La actividad verbal construye así, a la vez, la distención de la tensión y la tenacidad y el coraje con los que el pueblo enfrenta altivamente a su enemigo, el miedo. 
Como se puede advertir a partir del texto mismo reproducido más arriba, la actividad verbal, que es crítica al incremento de la tensión así como de su distención, no se actualiza en pasajes dialógicos en los que se dramatiza la interacción verbal de los personajes. La actividad verbal que se codifica es funcional, tal como hemos procurado reflejar, en términos de la caracterización evocada de los personajes y de la progresión de la acción. Sin embargo, se podría decir que los procesos verbales, en complementariedad con otros recursos en el texto, contribuyen al establecimiento de un diálogo en sentido más amplio: entre el pueblo que quiere expresar sus emociones y los opresores que pretenden acallarlos. Las acciones de los militares apostados a lo largo del camino hasta el cementerio con su actitud intimidatoria adquieren, como algunas de las acciones en el cuento anterior, una dimensión semiótica, expresan un mandato, y el canto de la Internacional por parte del pueblo es una respuesta indeseada a tal mandato en una interacción dialógica de carácter más amplio.

A medida que se despliega el texto, los procesos verbales sirven para caracterizar a los personajes y para hacer avanzar la acción y construyen, mediante un proceso de articulación simbólica, los temas centrales del texto. Los patrones de actividad material y verbal contribuyen a esta gradual construcción. La oposición entre la expresión de violencia brutal por parte de los militares y carabineros y la expresión valiente de emociones contenidas por parte de los manifestantes se construye, en parte, a partir de la actividad verbal y, más específicamente, de los rasgos particulares de articulación, volumen y vigor que los procesos conductuales al servicio de decir aportan. La fuerza de la expresión verbal expresa metafóricamente la fuerza colectiva del pueblo que se origina en la legitimidad de su reclamo y en el coraje de su expresión, aun cuando ésta signifique el enfrentar la manifestación ostentosa de fuerza de los militares. La contraposición entre estas dos fuerzas y el origen de su vigor (la violencia, por un lado, y la fuerza moral colectiva, por otro) constituyen uno de los temas que se construyen en el texto.

Por otro lado, el texto articula, en este episodio de la historia de Chile, un tema que atraviesa y da unidad a la trilogía Memoria del fuego: la búsqueda de la voz por parte del pueblo en Latino-América. Es posible distinguir, en esta viñeta, un movimiento progresivo hacia la expresión en la representación de la marcha del cortejo, desde la actividad no-verbal, gestual, por medio de las manos que saludan o el pañuelo que ondula, 
hasta la explosión del canto a todo pulmón de la Internacional que expresa verbalmente el afecto del pueblo. Este episodio refleja la progresión de la historia Latinoamericana hacia la búsqueda de la voz por parte de los oprimidos, que constituye un eje temático de la trilogía. Este es un camino por el que han transitado variados pueblos de Latinoamérica retratados a lo largo de todo el libro. En esta representación, los procesos verbales y, en particular aquellos en los cuales se infunden rasgos adicionales que evocan el afecto y los atributos de quienes transitaron el camino hacia el encuentro de su voz, cumplen un rol central en construir una de las orientaciones de la semántica más significativas de la narrativa de Galeano. Las variadas manifestaciones de la voz del oprimido, más o menos articuladas, más o menos expresadas en cantos, gritos, o locuciones construyen a lo largo del texto que nos ocupa y de todo el libro, lo que Hasan (1996: 54) llama los niveles más profundos de significado del texto literario, su tema. Estos significados resultan de la articulación simbólica que se produce entre las expresiones lingüísticas a las que tenemos acceso directo en el texto, en este caso, a las manifestaciones verbales del pueblo que se articulan una y otra vez, "calibrándose", en términos de Hasan (1996: 51), hasta constituir patrones que construyen la semántica de un nivel más profundo, es decir, los temas del texto.

En un orden aun más abstracto, estos patrones reflejan la perspectiva particular de Galeano sobre la historia americana, que tiñe la colección, su ideología o, como lo expresa Hassan, su visión o sus hipótesis sobre las condiciones de la existencia humana (Hasan 1996: 55). El autor construye a lo largo del libro su visión condenatoria de la autoridad forjada en la violencia y en el uso arbitrario y despiadado de la fuerza y, por otro, su valoración de la legitimidad y de la fuerza moral de la voz que el pueblo Latinoamericano construye paso a paso y que constituye su manera de enfrentar y resistir la fuerza violenta de la autoridad. En la actualización de estas orientaciones de orden más abstracto, contribuyen las selecciones lingüísticas que expresan las variadas manifestaciones de actividad verbal de los pueblos de Latino América construyendo así patrones y patrones de patrones en la logogénesis del texto.

Es interesante ver cómo, hacia el final del libro, Galeano expresa, de manera explícita, la centralidad de la actividad verbal en la construcción del rol del hombre y de la mujer en Latino América que se puede inferir de su manera particular de construir las narraciones a partir de lo lingüístico. 
En referencia a la marcha de un "ejército de voluntarios" nicaragüenses en 1980, Galeano describe la centralidad de lo verbal, y de lo que esta actividad, tan importante como el sustento más básico, refleja:

(7)

Ahora, a los tropezones, se echan a caminar. Van en busca del pan y la palabra: esta tierra, que abrió la boca, está ansiosa de comer y de decir. (Galeano 2006: 312)

\section{ConClusiones}

Las observaciones sobre las funciones que cumplen los procesos de "decir + cualidad" y "juicio" en los textos narrativos analizados permiten concluir que, al codificar la acción verbal, con todas las dimensiones contextuales y semánticas asociadas a ésta, estos procesos cumplen funciones muy importantes en la construcción del texto narrativo. En efecto, estos procesos están al servicio de la caracterización de los personajes en la narración ya que evocan, en virtud de sus propiedades semánticas, estados afectivos que el lector infiere de las propiedades acústicas de los procesos, o rasgos de personalidad, estado afectivo, etc., del Emisor, que se derivan del tipo de actitud expresado por éste. Estos procesos, además, cumplen la función de representar el tenor entre los personajes que interactúan en la narración, ya que el afecto evocado por los procesos de "decir + cualidad" y el tipo de juicio expresado por los procesos de "juicio" son propicios para la representación de las relaciones entre los interactuantes. En este último caso, los procesos verbales, y los procesos que nos ocupan en particular, son muy importantes para crear la impresión de realidad de la que Hassan habla al referirse a la relación as if (= como si) entre los interactuantes al interior del texto narrativo (Hassan 1996: 50). En ciertos textos donde la interacción verbal adquiere una significación especial por la tesis más general o profunda que el texto procura comunicar, estos procesos contribuyen a la articulación simbólica de tales significados a través de patrones de prominencia que establecen en el texto.

El análisis llevado a cabo permite también concluir que estos procesos contribuyen a la construcción del diálogo en un sentido más amplio, que abarca la naturaleza dialógica de la interacción en todas sus manifestaciones: la interacción con un interlocutor, la interacción consigo mismo y la interacción con los demás que se vale no solo de lo verbal, sino de otros recursos semióticos como la acción. 
Recebido em outubro de 2011 Aprovado em dezembro de 2011 Emails:gsalmaso@gmail.com cristinaboccia@gmail.com lauraeugeniah@gmail.com

\section{Bibliografía}

Cortázar, Julio. 1996. Las manos que crecen. En: Cuentos Completos/1. Buenos Aires: Alfaguara, 36-42.

DAVIDSE, Kristin. 1999. Categories of Experiential Grammar. Nottingham: Nottingham Trent University.

Galeano, Eduardo. 1982. Memoria del fuego I y II. Argentina: Catálogos. .2006. Memoria del Fuego III. El siglo del viento. España: Siglo Veintiuno editores.

. La casa de Neruda. En: Memoria del Fuego III. El siglo del viento. España: Siglo Veintiuno editores, 262-263.

Halliday, M. A. K. 1971, 2002. Linguistic Function and Literary Style: An Inquiry into the Language of William Golding's The Inheritors. En: Webster, Jonathan, ed. Linguistic Studies of Text and Discourse. The Collected Studies of M. A. K. Halliday, vol. II. Continuum, 88-125.

Halliday, M. A. K y Christian Matthiessen. 2004. An Introduction to Functional Grammar. London: Arnold, $3^{\text {rd }}$ edition.

Hassan, Ruqayia. 1985. Linguistics, Language and Verbal Art. Oxford: Oxford University Press. . 1996. On Teaching Literature Across Cultural Distances. En: Joyce, James, ed. The Language-Culture Connection. Singapore: SEAMEO Regional Language Center: 34-63.

Matthiessen, Christian. 1995. Lexico-grammatical Cartography: English Systems. Tokyo: International Language Sciences Publishers.

White, Peter y James Martin. 2005. The Language of Evaluation. Appraisal in English. New York: Palgrave Macmillan. 